\title{
Controlling the Width of Weld Bead from the Weld Pool Using Machine Vision and Artificial Neural Network
}

\author{
Ario Sunar Baskoro, ${ }^{1, *}$, Duvall Anggraita Purwanto ${ }^{1}$, and Agus Widyianto ${ }^{1}$ \\ ${ }^{1}$ Department of Mechanical Engineering, Faculty of Engineering, Universitas Indonesia, Depok 16424, Indonesia
}

\begin{abstract}
In this study, the development of artificial neural network systems was proposed to keep the width of weld bead constant by controlling the welding speed. During Gas Tungsten Arc Welding, the weld bead was observed directly using machine vision system that utilized CCD camera. Matlab software was used for image processing algorithm and training the data. In training the data, two methods were used which are training with normalization and without normalization. ANN input parameters were arc current, welding speed, number of pixel and location of weld bead. Double hidden layer was used where each one of them consists of 25 nodes, and the output parameter is new controlled welding speed. The testing data was performed using 100, 105 and 110 A with initial welding speed of $1.35,1.40$ and $1.45 \mathrm{~mm} / \mathrm{s}$. The measurement of weld bead was taken using two different methods, machine vision and manual measurement. The result showed that the width of weld bead on welding current of $105 \mathrm{~A}$ is close to the target of $7 \mathrm{~mm}$ with the average error of $0.49 \mathrm{~mm}$. The best result for the machine vision and manual measurement can be achieved when the welding current is $110 \mathrm{~A}$ with a normalization.
\end{abstract}

\section{Introduction}

Welding is very important in industrial sector for joining materials. And automated welding is needed to decrease production cost, improve productivity and improve the safety of working environment [1]. Gas Tungsten Arc Welding (GTAW) is often used in practice as pipe, vessel, metals plate and etc. TIG welding can be operated without employing filler metals or it was called autogenous welding [2]. A filler metals are employed when the materials are higher than $3 \mathrm{~mm}$ of thickness.

Width of weld bead is an important physical property of a weldment. The width of weld bead is influenced by welding current and welding speed. It occurs because the effect of high heat input in the welding area [3]. Distortion and residual stress can also be determined from the width of weld bead [4]. An automatic welding control system can replace manual welding process to control width of weld bead during welding process. To perform that assignment, some research used CCD camera as a vision sensor to monitor the width of weld pool, then regulate the welding parameter [5-7]. The weld bead image taken during the welding process is used to control the welding speed using artificial neural networks [8].

The modeling with strong data that is capable of capturing and representing complex input and output relationships is the function of artificial neural network (ANN) [9]. ANN can be used to predict or control kinds of things for example the width of weld bead. It can be used to model complex relationships between input and output to find patterns in the data. The input and output variables are used to determine relationships without the need to specify the relationship between variables. In recent years, Nagesh reported using ANN to predicted the weld bead geometry [10] and deep penetration [4]. In addition, it also uses infrared sensing techniques to calculate the weld bead geometry [10-14]. Lee and Um [15] used artificial neural network and fuzzy logic to predict the weld bead geometry, microstructure, defect and recognition. Nandhitha [16] predicted the welding current using ANN by monitoring the lack of penetration of IR thermal images.

Artificial neural networks are very effective to use because the processing time is short to produce output, so it can be used to control the width of weld bead directly [17]. Therefore, the present experiment attempts to develop control systems to control the width of weld bead using artificial neural network in aluminum 6063 TIG welding. The input parameters include various images of weld bead width, which were extracted using image processing algorithm. The new welding speed was the output to control the width of weld bead.

\section{Experiment methods}

Thin aluminum alloy Al 6063 plates were used in the experiment with the dimensions of $50 \times 120 \mathrm{~mm}$ and thickness of $3 \mathrm{~mm}$. A GeKaMac power TIG 2200 AC machine was used to joint the plates. Table 1 shows the specification of GeKaMac welding machine. 
Table 1. Specification of GeKaMac welding machine [18]

\begin{tabular}{cc}
\hline Model & TIG \\
\hline Input & $230 \mathrm{~V}, 50-60 \mathrm{~Hz}, 1$ Phase \\
Fuse & $16 \mathrm{~A}$ \\
Installed Power & $6.3 \mathrm{kVA}$ \\
Current Range & $5-220 \mathrm{~A}$ \\
Duty Cycle at & $\% 60130 \mathrm{~A}$ \\
Dimensions $(\mathrm{mm})$ & $465 \times 185 \times 390$ \\
Weight $(\mathrm{kg})$ & 15.5 \\
\hline
\end{tabular}

Argon gas was used to avoid oxidation and for shielding gas. The welding process was conducted without a filler or autogenous welds. A Guppy Pro F032B CCD camera was used for monitoring weld bead and captured the image to the process control computer where the image processing occurs. The Guppy Pro F032B CCD have a resolution of $656 \times 492$, maximum frame rate of $82 \mathrm{fps}$ with IEEE1394b interface.

The CCD camera was placed at an angle of 30 degrees. The schematic of experimental apparatus illustration is shown on Fig.1. Chemical compositions of the aluminum used are given in Table 3. Before welding, the surface of the specimens were cleaned by 400 grit flexible abrasive papers. After that, it were chemically cleaned with acetone solution to remove surface impurities.

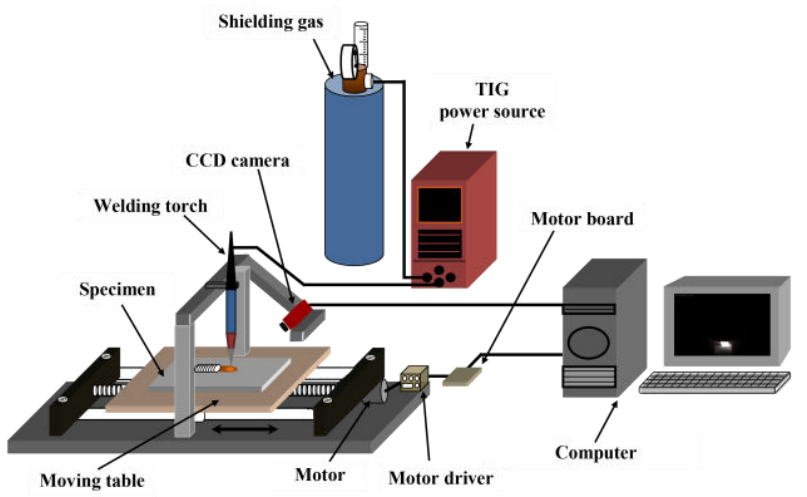

Fig. 1. Schematic of welding apparatus

Tabel 2. Chemical composition of the $\mathrm{Al} 6063$ aluminum (\% by weight)

\begin{tabular}{c|c|c|c|c|c}
\hline \multirow{4}{*}{$\mathrm{Al}$} & $\mathrm{Si}$ & $\mathrm{Fe}$ & $\mathrm{Cu}$ & $\mathrm{Mg}$ & $\mathrm{Mn}$ \\
\cline { 2 - 6 } 6063 & 0.45 & 0.30 & 0.10 & 0.65 & 0.10 \\
\cline { 2 - 6 } & $\mathrm{Cr}$ & $\mathrm{Zn}$ & $\mathrm{Ti}$ & $\mathrm{Al}$ & \\
\cline { 2 - 5 } & 0.10 & 0.10 & 0.10 & $\mathrm{Bal}$. & \\
\hline
\end{tabular}

The next process for investigated of weld quality, CCD camera was used to capture the molten pool image during welding process and stehtored in a computer. The schematic of CCD camera for capturing the molten pool illustration is shown on Fig.2.

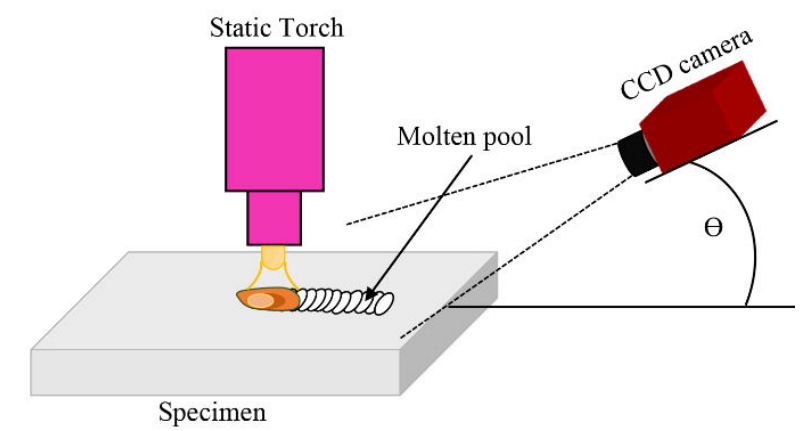

Fig. 2. Schematic of CCD camera

The image will be processed using Matlab 2013b software using image processing algorithm. Figure 3 shows the image processing algorithm to determine the width of weld bead. After capturing the image of molten pool in Fig. 3 (a), then the image was transformed into grayscale image as shown in Fig. 3 (b). By thresholding techniques, the image will be turned into binary value pixel or black and white (BW) image and made it easier in the detection process. Afterwards, used "medfilt2 filter" to removed noise in point form and "bwareaopen filter" to eliminate large noise (see Fig. 3 (c) and (d)). Several pixel measurement as shown in Fig. 3 (e) were conducted, and the biggest results of pixel measurement will be considered as the weld pool width. It was necessary to get the ratio between the real width of the weld pool with the number of pixels and to find the real width of the weld pool that have been captured.
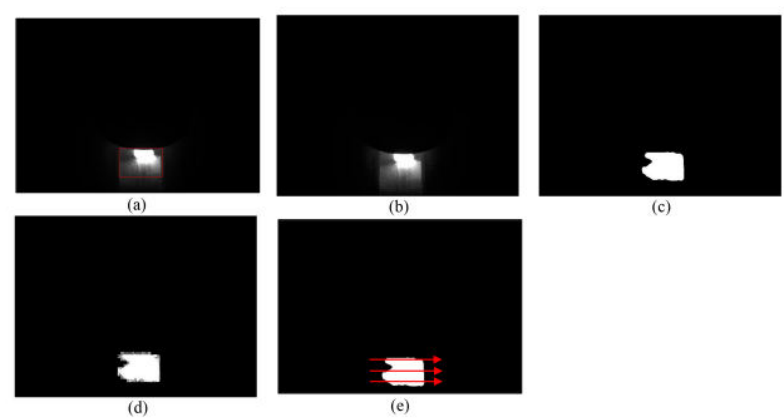

Fig. 3. Image processing result: (a) Original image of molten pool, (b) Grayscale image, (c) Medfilt2 image, (d) Bwareaopen image, (e) Detected width of molten pool.

The next process was comparing the manual measurement on the weld bead with the result of machine vision measurement on the weld pool that recorded from images during welding process. This process was conducted to calibration the two types measurements. The result of calibration was 1 pixel equal to $0.06 \mathrm{~mm}$.

The first experiment was used to search initial data with variations of the welding current and welding speed without CCD camera. After getting the initial data, then determine the target of weld bead width for the next experiment. The second experiment used CCD camera to 
observe the molten pool. In this experiment, initial data in previous experiment was used to control the width of weld bead using ANN which hasn't been normalized. The third experiment almost the same as the second experiment, but in this stage, the artificial neural network system has been normalized.

The welding condition and parameter of the process that were used in this experiment is shown in Table 4. The parameters were used by varying arc current and welding speed. During the welding process the CCD camera takes pictures of the weld pool and stores it on the computer. The best combination parameters and results are shown in Table 5. The values in Table 5 will become the reference and parameter in next experiment.

Table 3. Welding conditions used in the experiment

\begin{tabular}{lll}
\hline Parameter & Unit & Value \\
\hline Power source & Dimensionless & DCEN \\
Welding current & $\mathrm{A}$ & $100-110$ \\
Welding speed & $\mathrm{mm} / \mathrm{sec}$ & $1.35-1.45$ \\
AWS classification & Dimensionless & $2 \% \mathrm{Th}-\mathrm{W}$ \\
Electrode diameter & $\mathrm{mm}$ & 1.6 \\
Nominal arc length & $\mathrm{mm}$ & 1 \\
Shielding gas & Dimensionless & $99,99 \%$ Argon \\
Shielding gas flow rate & L/min & 10 \\
\hline
\end{tabular}

Table 4. The best combination parameter

\begin{tabular}{ccc}
\hline $\begin{array}{c}\text { Welding Current } \\
(\mathrm{A})\end{array}$ & $\begin{array}{c}\text { Welding Speed } \\
(\mathrm{mm} / \mathrm{s})\end{array}$ & $\begin{array}{c}\text { Average Weld Bead } \\
\text { Width }(\mathrm{mm})\end{array}$ \\
\hline 100 & 1.4 & 7.61 \\
105 & 1.4 & 8.25 \\
110 & 1.45 & 8.78 \\
\hline
\end{tabular}

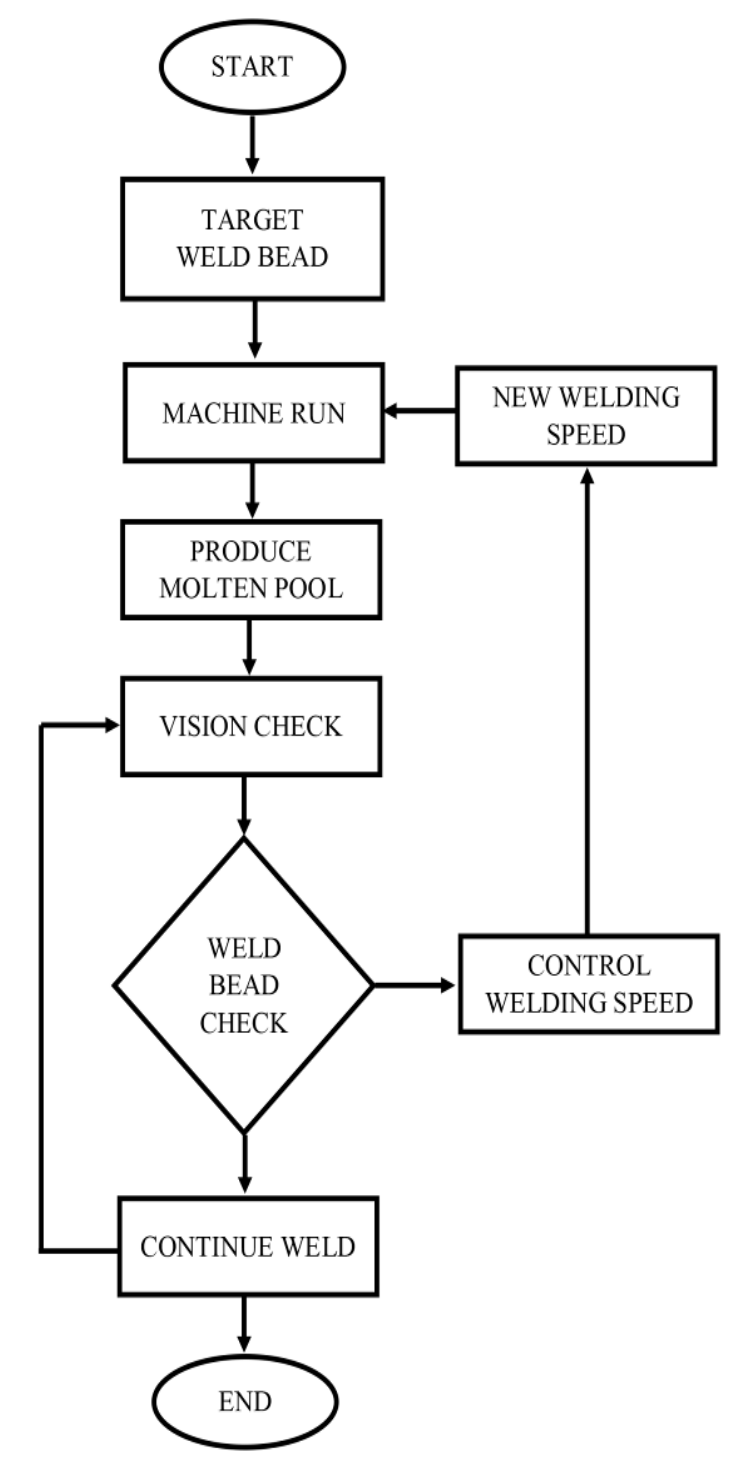

Fig. 4. Schematic flow chart control artificial neural network system

Figure 4 shows the system flowchart of control for artificial neural network. Then the next experiment is to control the welding speed using artificial neural network using the width of weld bead for controlling as shown in Fig. 5. This shows that each measurement of the width of weld bead will be compared with the target width of weld bead. 


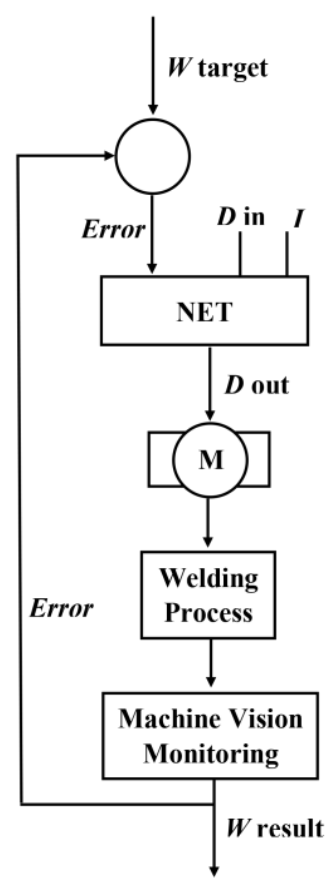

Fig. 5. Schematic diagram of welding speed control system

The difference value between the value of weld bead width from the measurement and target is called error. The error will be studied by artificial neural network to obtain the target of weld bead width using controlled welding speed. The artificial neural network has been built to predict proper speed, as shown in Fig.6. There were four input data in input layer to train the process which were arc current, welding speed, number of pixel and welding position. The next layer was two hidden layer that consists of 25 nodes each and the output layer was new welding speed.

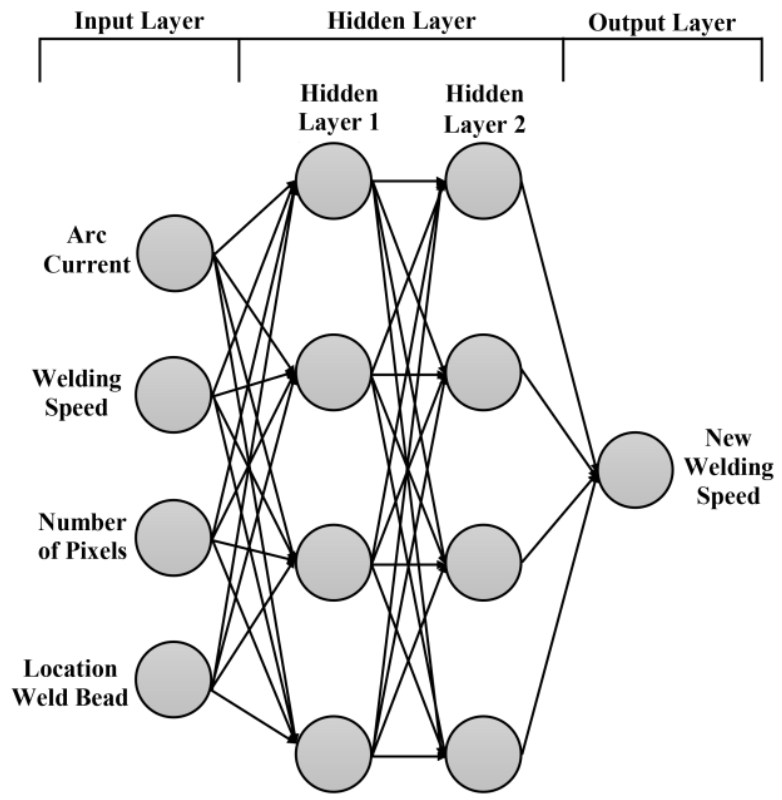

Fig. 6. Neural network model

This experiment was carried out with the welding speed control systems refers to the previous experiment as shown in Table 5. The arc current variation used were
$100,105 \mathrm{~A}$ and $110 \mathrm{~A}$ with the width of weld bead target was $7 \mathrm{~mm}$.

\section{Results and discussion}

\subsection{Initial experiment without artificial neural network control}

Variations in welding current and welding speed have been carried out to obtain the width of the weld bead. After that the width of weld beadwas measured at 9 points, started $10 \mathrm{~mm}$ from the start point until $10 \mathrm{~mm}$ before the end point. Figure 7 shows the comparison of weld bead width and welding speed. Those data was collected and used for training the neural network system.

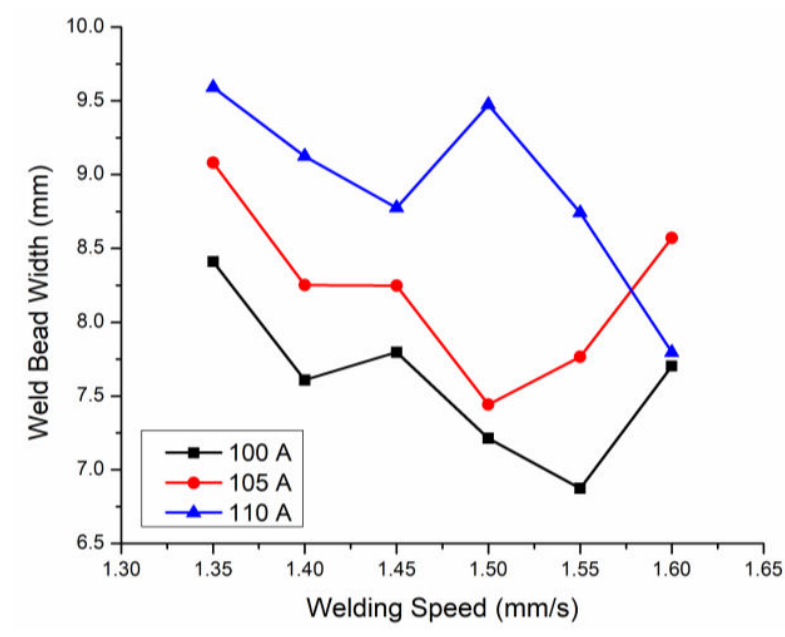

Fig. 7. Comparison of weld bead width and welding speed

Figure 7 shows the different weld bead width with variations of welding speed in 9 location and it was used $100 \mathrm{~A}, 105 \mathrm{~A}$, and $110 \mathrm{~A}$ of weld current. By increasing the welding speed, the width of weld bead could be minimized. It because of heat transfer speed in material, if the welding speed moved slowly, it could affect the width of weld bead become widen. Figure 8 (a) and (b) shows the appearance of the width of weld bead of 105 $\mathrm{A}$ and $110 \mathrm{~A}$, respectively. Finally, the welding speed parameters were selected from $1.35 \mathrm{~mm} / \mathrm{s}, 1.4 \mathrm{~mm} / \mathrm{s}$, and $1.45 \mathrm{~mm} / \mathrm{s}$ as the initial welding speed. It was used to train the data of artificial neural network in next experiment.

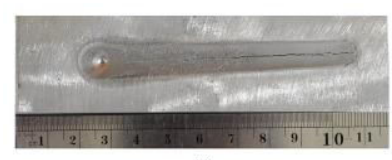

(a)

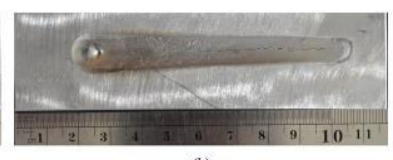

(b)
Fig. 8. Appearance of weld bead on initial data: (a) $105 \mathrm{~A}$ and (b) $110 \mathrm{~A}$ 


\subsection{Experiment with artificial neural network control}

The next experiment was conducted by making an automatic welding speed control using artificial neural network. The width of weld bead data in the previous experiment was used to predict the width of weld bead in the next experiment. The width of weld bead that occurs after the welding process was captured using a CCD camera and stored on the computer. This experiment was performed twice, first using the initial data without normalization and second using the previous data with normalization. The variation of welding current used in this experiment from 100 A to 110 A with an increase of $5 \mathrm{~A}$ and the initial welding speed from $1.35 \mathrm{~mm} / \mathrm{s}$ to 1.45 $\mathrm{mm} / \mathrm{s}$ with an increase of $0.05 \mathrm{~mm} / \mathrm{s}$.

\subsubsection{Welding experiment without normalization}

Figure 9 shows the comparison results from manual measurement and machine vision measurement of weld bead width, and welding speed from image processing process without normalization of $100 \mathrm{~A}$. The width of weld bead that was produced from the start point to the end of the welding point was widening. Figure 9 (a) have initial welding speeds of $1.35 \mathrm{~mm} / \mathrm{s}, 1.40 \mathrm{~mm} / \mathrm{s}$ and 1.45 $\mathrm{mm} / \mathrm{s}$, respectively. The initial welding speed can adjust with increasing the width of weld bead but the results were not significant. The result of weld bead width in manual and machine vision measurement can be compared to the target of weld bead and to find the error and standard deviation.

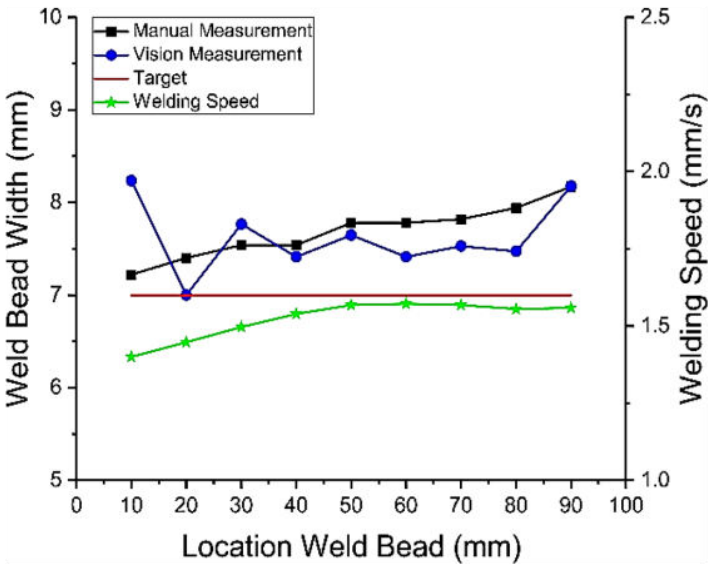

(a)

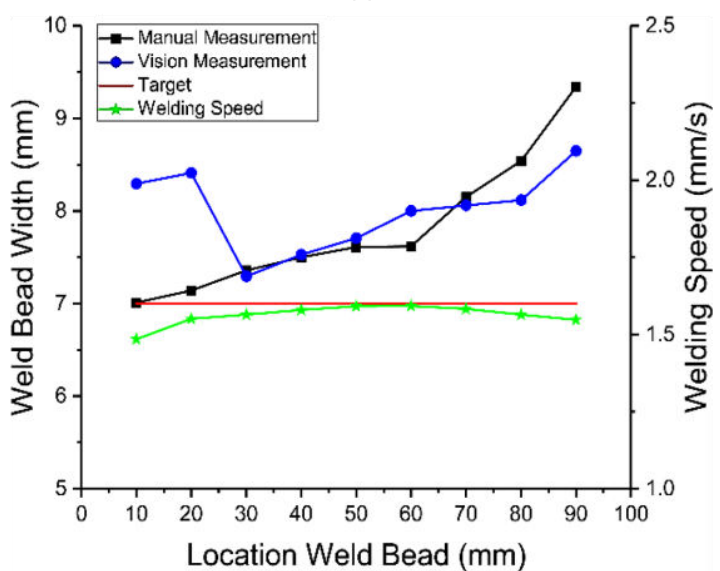

(b)

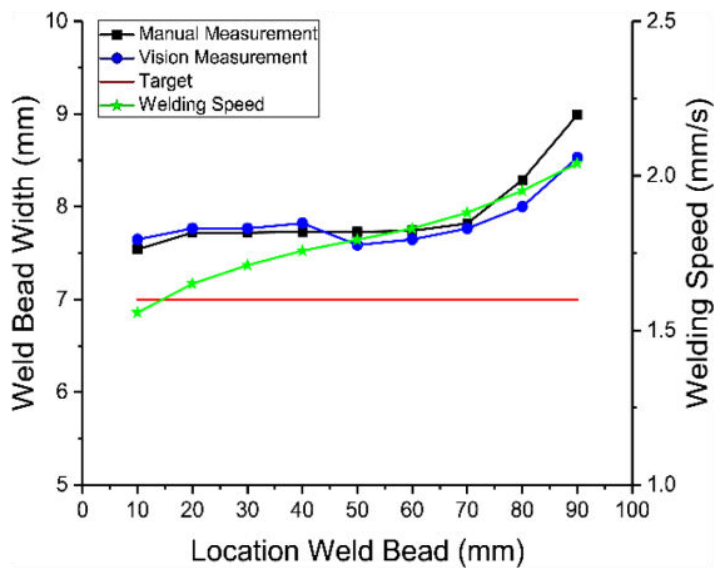

(c)

Fig. 9. Comparison of weld bead width without normalization of $100 \mathrm{~A}$ and initial welding speed, (a) $1.35 \mathrm{~mm} / \mathrm{s}$, (b) 1.40 $\mathrm{mm} / \mathrm{s}$ and (c) $1.45 \mathrm{~mm} / \mathrm{s}$ 


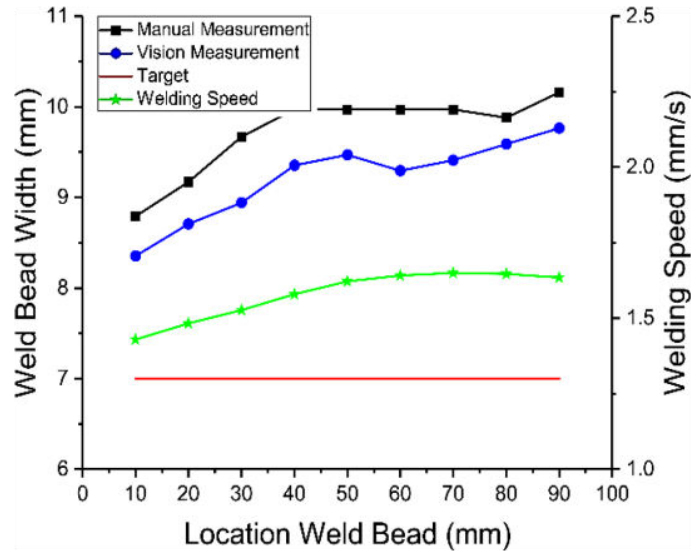

(a)

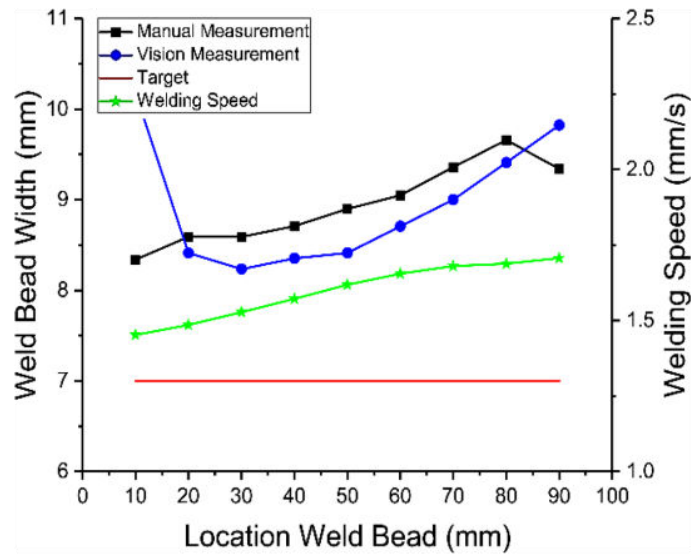

(b)

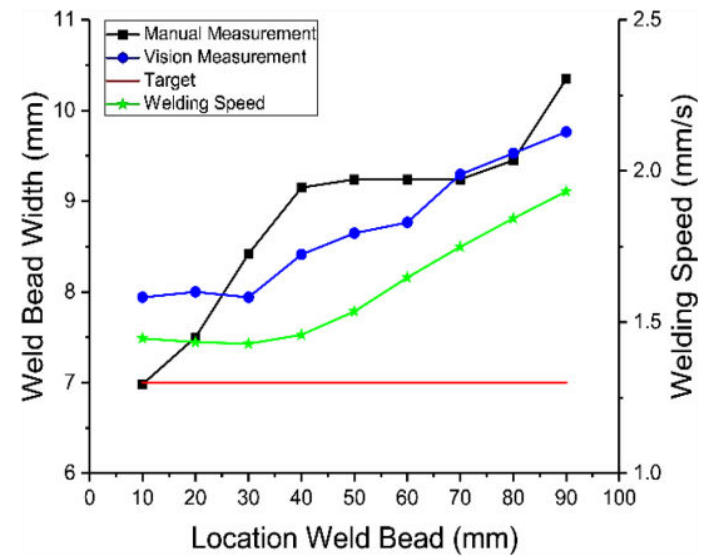

(c)

Fig. 10. Comparison of weld bead width without normalization of $105 \mathrm{~A}$ and initial welding speed, (a) $1.35 \mathrm{~mm} / \mathrm{s}$, (b) 1.40 $\mathrm{mm} / \mathrm{s}$ and (c) $1.45 \mathrm{~mm} / \mathrm{s}$

Figure 10 shows the comparison results from manual measurement and machine vision measurement of weld bead width, and welding speed from image processing process without normalization of $105 \mathrm{~A}$. Figure 10 (a) have initial welding speeds of $1.35 \mathrm{~mm} / \mathrm{s}$, $1.40 \mathrm{~mm} / \mathrm{s}$ and $1.45 \mathrm{~mm} / \mathrm{s}$, respectively.

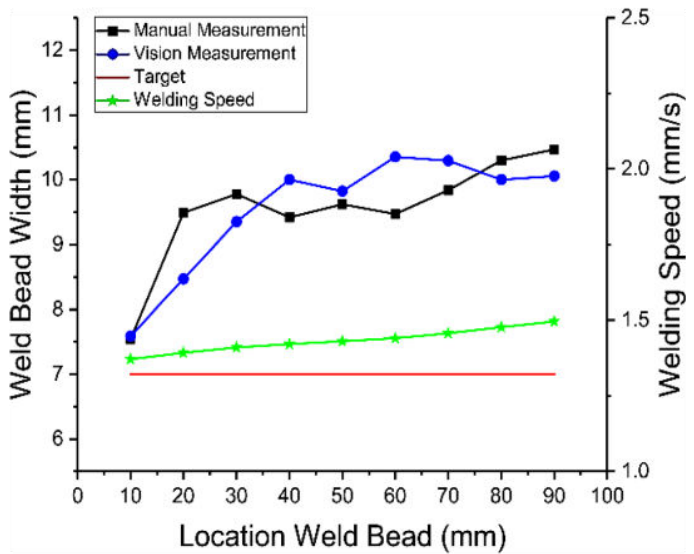

(a)

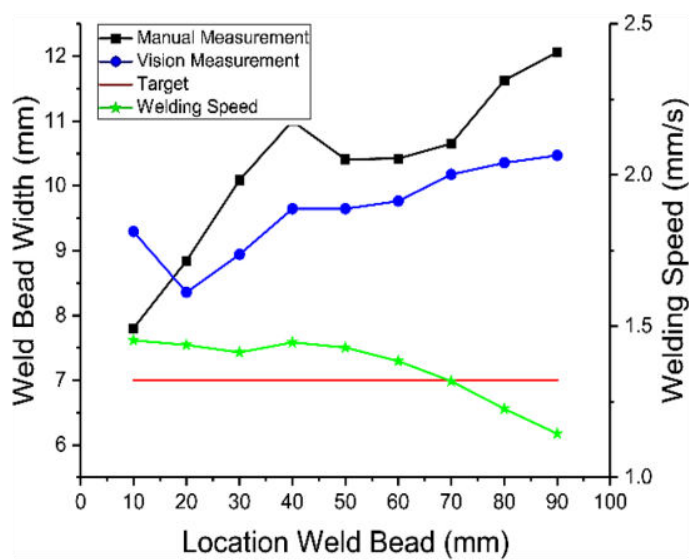

(b)

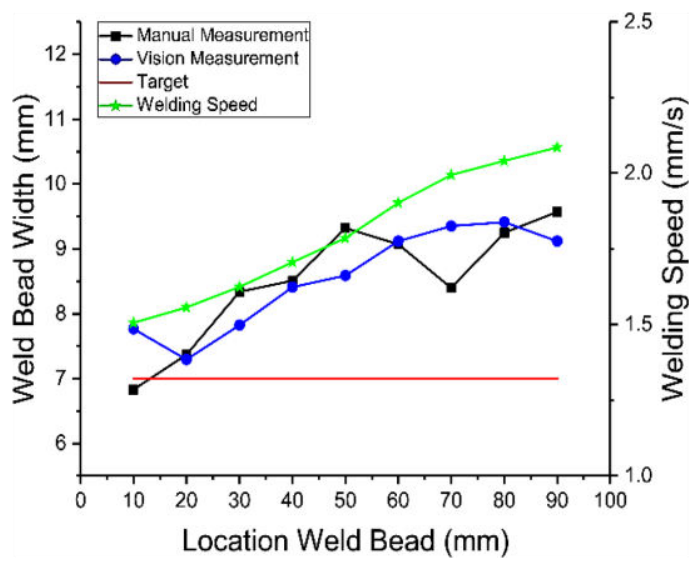

(c)

Fig. 11. Comparison of weld bead width without normalization of $110 \mathrm{~A}$ and initial welding speed, (a) $1.35 \mathrm{~mm} / \mathrm{s}$, (b) 1.40 $\mathrm{mm} / \mathrm{s}$ and (c) $1.45 \mathrm{~mm} / \mathrm{s}$

Figure 11 shows the comparison results from manual measurement and machine vision measurement of weld bead width, and welding speed from image processing process without normalization of $110 \mathrm{~A}$. Figure 11 (a) have initial welding speeds of $1.35 \mathrm{~mm} / \mathrm{s}$, $1.40 \mathrm{~mm} / \mathrm{s}$ and $1.45 \mathrm{~mm} / \mathrm{s}$, respectively. Increasing the welding current can widen the weld bead, but increasing the initial welding speed can reduce the weld bead.

The summary of the average results is shown in Table 5. In manual measurements, the results are closed to the target of weld bead when weld current at $100 \mathrm{~A}$, the average error and the average standard deviation of $0.81 \mathrm{~mm}$ and $0.50 \mathrm{~mm}$, respectively. In machine vision 
measurement, the average error and the average standard deviation of $0.82 \mathrm{~mm} 0.37 \mathrm{~mm}$, respectively.

Table 5. The width of weld bead of manual and machine vision measurement without normalization

\begin{tabular}{|c|c|c|c|c|}
\hline \multirow[b]{2}{*}{$\begin{array}{l}\text { Current } \\
\text { (A) }\end{array}$} & \multirow[b]{2}{*}{$\begin{array}{l}\text { Target } \\
(\mathrm{mm})\end{array}$} & \multicolumn{2}{|c|}{ Average result } & \multirow[b]{2}{*}{$\begin{array}{l}\text { Standard } \\
\text { deviation }\end{array}$} \\
\hline & & $\begin{array}{c}\text { Manual } \\
\text { measurement } \\
(\mathrm{mm})\end{array}$ & $\begin{array}{l}\text { Error } \\
(\mathrm{mm})\end{array}$ & \\
\hline 100 & \multirow{3}{*}{7} & 7.81 & 0.81 & 0.50 \\
\hline 105 & & 9.17 & 2.17 & 0.64 \\
\hline 110 & & 9.46 & 2.46 & 1.00 \\
\hline \multirow[b]{2}{*}{$\begin{array}{c}\text { Current } \\
\text { (A) }\end{array}$} & \multirow[b]{2}{*}{$\begin{array}{l}\text { Target } \\
(\mathrm{mm})\end{array}$} & \multicolumn{2}{|c|}{ Average result } & \multirow[b]{2}{*}{$\begin{array}{l}\text { Standard } \\
\text { deviation }\end{array}$} \\
\hline & & $\begin{array}{c}\text { Machine } \\
\text { vision } \\
\text { measurement } \\
(\mathrm{mm})\end{array}$ & $\begin{array}{l}\text { Error } \\
(\mathrm{mm})\end{array}$ & \\
\hline 100 & \multirow{3}{*}{7} & 7.82 & 0.82 & 0.37 \\
\hline 105 & & 8.95 & 1.95 & 0.62 \\
\hline 110 & & 9.24 & 2.24 & 0.80 \\
\hline
\end{tabular}

Table 6. Comparison the width of weld bead of manual and machine vision measurement without normalization

\begin{tabular}{|c|c|c|c|c|}
\hline \multirow{2}{*}{$\begin{array}{c}\text { Current } \\
(\mathrm{A})\end{array}$} & $\begin{array}{c}|c| \\
\text { Manual } \\
\text { measurement } \\
(\mathrm{mm})\end{array}$ & $\begin{array}{c}\text { Machine } \\
\text { vision } \\
\text { measurement } \\
(\mathrm{mm})\end{array}$ & $\begin{array}{c}\text { Error } \\
(\mathrm{mm})\end{array}$ & $\begin{array}{c}\text { Standard } \\
\text { deviation }\end{array}$ \\
\hline 100 & 7.81 & 7.82 & 0.11 & 0.31 \\
\hline 105 & 9.17 & 8.95 & 0.22 & 0.31 \\
\hline 110 & 9.46 & 9.24 & 0.24 & 0.37 \\
\hline
\end{tabular}

Table 6 shows the comparison results from manual and machine vision measurement of weld bead width without normalization. The lowest measurement difference can be achieved at weld current of $100 \mathrm{~A}$ with the average error and the average standard deviation of $0.11 \mathrm{~mm}$ and $0.31 \mathrm{~mm}$, respectively. This error occurs because some errors from the image processing algorithm such as threshold value, error of edge detection, the construction of neural network and training parameters [19]. The appearance of weld bead width is shown in figure 12 (a) and (b), respectively.
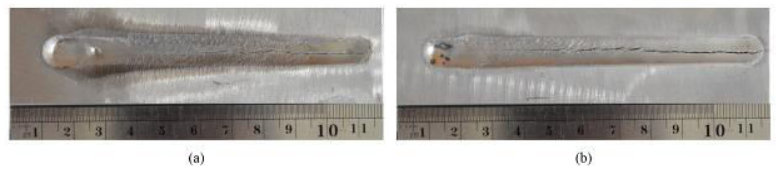

Fig. 12. Appearance of weld bead without normalization, (a) $105 \mathrm{~A}$ and (b) $110 \mathrm{~A}$

\subsubsection{Welding experiment with normalization}

Figure 13 shows the comparison results from manual and machine vision measurement of weld bead width, and welding speed from image processing process with normalization of $100 \mathrm{~A}$. The width of weld bead that was produced from the start point to the end of the welding point can be kept constant. Figure 13 (a) have initial welding speeds of $1.35 \mathrm{~mm} / \mathrm{s}, 1.40 \mathrm{~mm} / \mathrm{s}$ and $1.45 \mathrm{~mm} / \mathrm{s}$, respectively. In this experiment, the initial welding speed can adjust with increasing the width of weld bead.

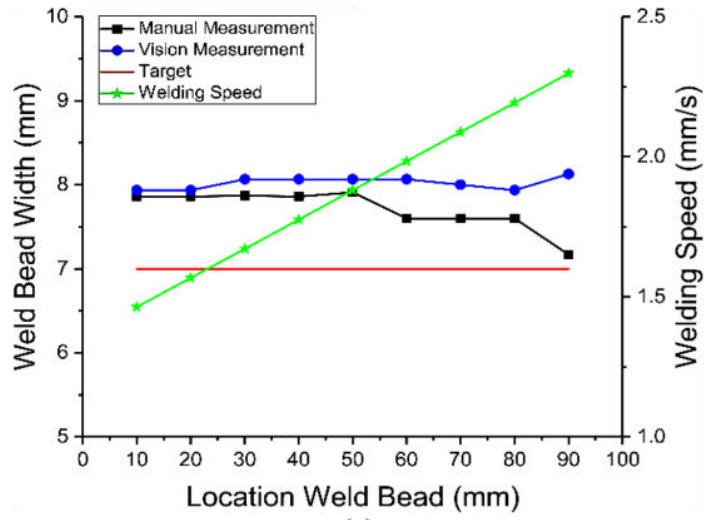

(a)

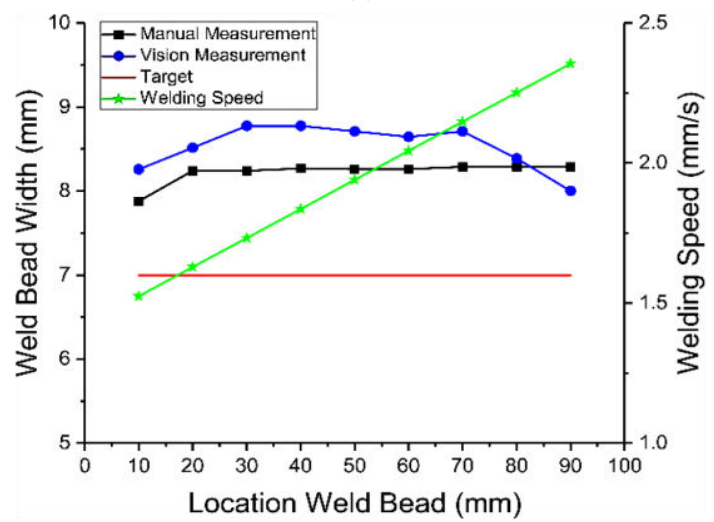

(b)

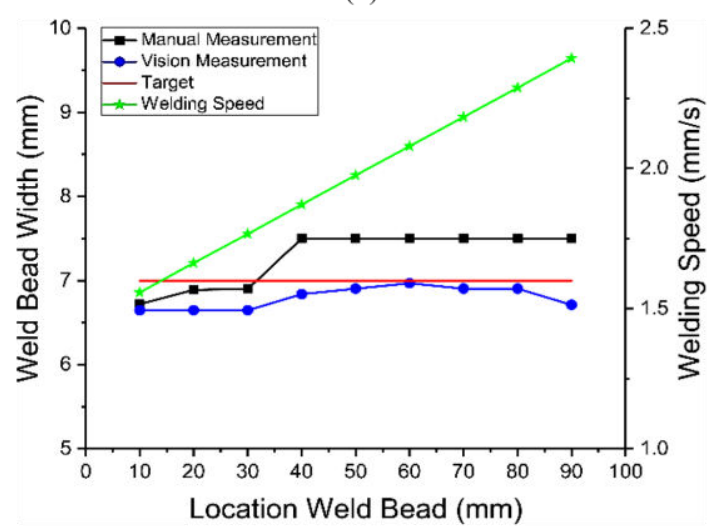

(c)

Fig. 13. Comparison of weld bead width with normalization of $100 \mathrm{~A}$ and initial welding speed, (a) $1.35 \mathrm{~mm} / \mathrm{s}$, (b) $1.40 \mathrm{~mm} / \mathrm{s}$ and (c) $1.45 \mathrm{~mm} / \mathrm{s}$ 


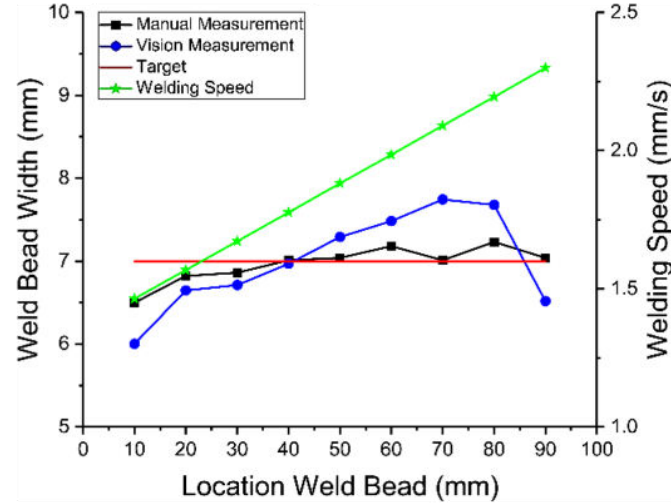

(a)

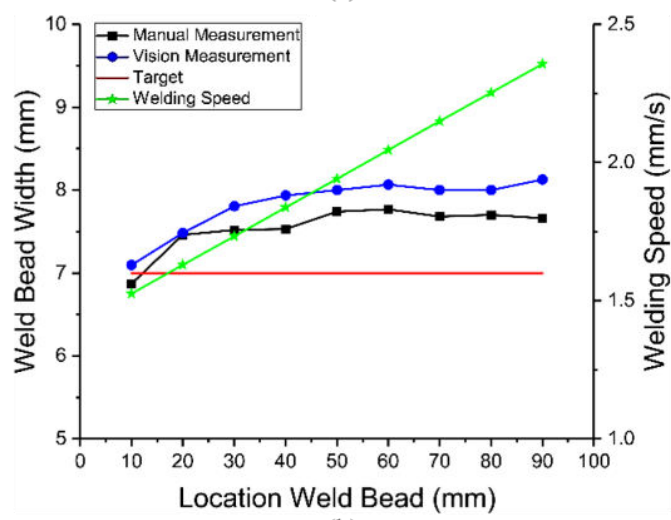

(b)

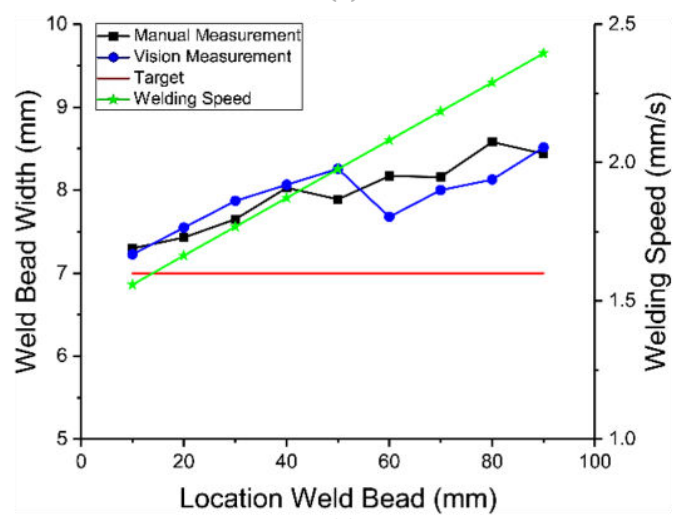

(c)

Fig. 14. Comparison of weld bead width with normalization of $100 \mathrm{~A}$ and initial welding speed, (a) $1.35 \mathrm{~mm} / \mathrm{s}$, (b) $1.40 \mathrm{~mm} / \mathrm{s}$ and (c) 1.45 $\mathrm{mm} / \mathrm{s}$

Figure 14 shows the comparison results from manual measurement and machine vision measurement of weld bead width, and welding speed from image processing process without normalization of $105 \mathrm{~A}$. Figure 14 (a) have initial welding speeds of $1.35 \mathrm{~mm} / \mathrm{s}$, $1.40 \mathrm{~mm} / \mathrm{s}$ and $1.45 \mathrm{~mm} / \mathrm{s}$, respectively.

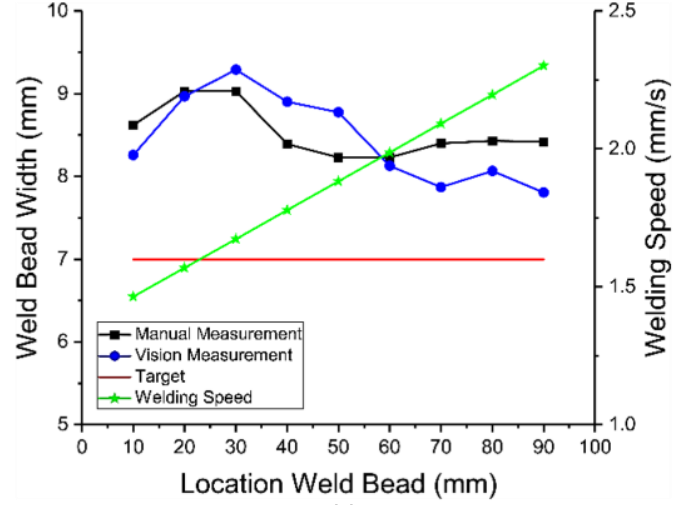

(a)

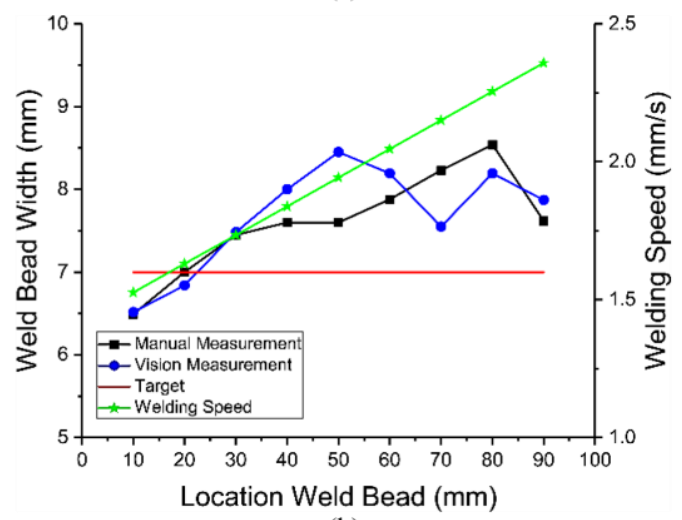

(b)

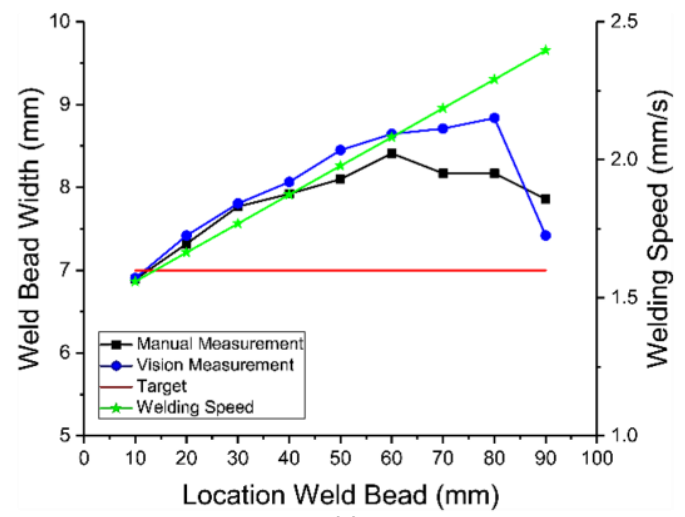

(c)

Fig. 15. Comparison of weld bead width with normalization of $100 \mathrm{~A}$ and initial welding speed, (a) $1.35 \mathrm{~mm} / \mathrm{s}$, (b) $1.40 \mathrm{~mm} / \mathrm{s}$ and (c) 1.45 $\mathrm{mm} / \mathrm{s}$

Figure 15 shows the comparison results from manual measurement and machine vision measurement of weld bead width, and welding speed from image processing process without normalization of $110 \mathrm{~A}$. Figure 15 (a) have initial welding speeds of $1.35 \mathrm{~mm} / \mathrm{s}$, $1.40 \mathrm{~mm} / \mathrm{s}$ and $1.45 \mathrm{~mm} / \mathrm{s}$, respectively. In this experiment can be shown a significant increase in welding speed to get the width of weld beadthat was close to the target.

The summary of the average results is shown in Table 7. In this experiment, the overall result closer to the target than previous experiment. In manual measurement, the closest result can be achieved at 105 $\mathrm{A}$, the average error and the average standard deviation of $0.49 \mathrm{~mm}$ and $0.26 \mathrm{~mm}$, respectively. In machine vision measurement, the average error and the average 
standard deviation of $0.59 \mathrm{~mm}$ and $0.34 \mathrm{~mm}$, respectively.

Table 7. The width of weld bead of manual and machine vision measurement with normalization

\begin{tabular}{|c|c|c|c|c|}
\hline \multirow[b]{2}{*}{$\begin{array}{l}\text { Current } \\
\text { (A) }\end{array}$} & \multirow[b]{2}{*}{$\begin{array}{l}\text { Target } \\
(\mathrm{mm})\end{array}$} & \multicolumn{2}{|c|}{ Average result } & \multirow[b]{2}{*}{$\begin{array}{r}\text { Standard } \\
\text { deviation }\end{array}$} \\
\hline & & $\begin{array}{c}\text { Manual } \\
\text { measurement } \\
(\mathrm{mm})\end{array}$ & $\begin{array}{l}\text { Error } \\
(\mathrm{mm})\end{array}$ & \\
\hline 100 & \multirow{3}{*}{7} & 7.74 & 0.74 & 0.18 \\
\hline 105 & & 7.49 & 0.49 & 0.26 \\
\hline 110 & & 7.99 & 0.99 & 0.39 \\
\hline \multirow[b]{2}{*}{$\begin{array}{l}\text { Current } \\
\text { (A) }\end{array}$} & \multirow[b]{2}{*}{$\begin{array}{l}\text { Target } \\
(\mathrm{mm})\end{array}$} & \multicolumn{2}{|c|}{ Average result } & \multirow[b]{2}{*}{$\begin{array}{l}\text { Standard } \\
\text { deviation }\end{array}$} \\
\hline & & $\begin{array}{c}\text { Machine } \\
\text { vision } \\
\text { measurement } \\
(\mathrm{mm}) \\
\end{array}$ & $\begin{array}{l}\text { Error } \\
(\mathrm{mm})\end{array}$ & \\
\hline 100 & \multirow{3}{*}{7} & 7.78 & 0.78 & 0.16 \\
\hline 105 & & 7.59 & 0.59 & 0.34 \\
\hline 110 & & 8.05 & 1.05 & 0.54 \\
\hline
\end{tabular}

Table 8. Comparison the width of weld bead of manual and machine vision measurement with normalization

\begin{tabular}{|c|c|c|c|c|}
\hline \multirow{2}{*}{$\begin{array}{c}\text { Current } \\
(\mathrm{A})\end{array}$} & $\begin{array}{c}\text { Manual } \\
\text { measurement } \\
(\mathrm{mm})\end{array}$ & $\begin{array}{c}\text { Machine } \\
\text { vision } \\
\text { measurement } \\
(\mathrm{mm})\end{array}$ & $\begin{array}{c}\text { Error } \\
(\mathrm{mm})\end{array}$ & $\begin{array}{c}\text { Standard } \\
\text { deviation }\end{array}$ \\
\hline 100 & 7.74 & 7.78 & 0.37 & 0.22 \\
\hline 105 & 7.49 & 7.59 & 0.12 & 0.17 \\
\hline 110 & 7.99 & 8.05 & 0.11 & 0.24 \\
\hline
\end{tabular}

Table 8 shows the comparison results from manual and vision measurement of weld bead width with normalization. The lowest measurement difference can be achieved at weld current of $110 \mathrm{~A}$ with the average error and the average standard deviation of $0.11 \mathrm{~mm}$ and $0.24 \mathrm{~mm}$, respectively. The appearance of weld bead width is shown in figure 16 (a) and (b), respectively.
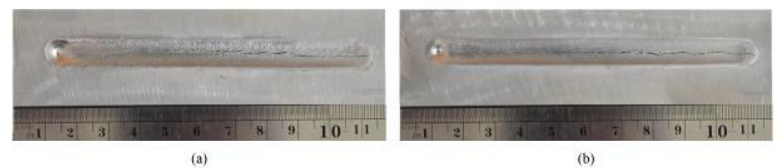

Fig. 16. Appearance of weld bead with normalization: (a) 105 A and (b) $110 \mathrm{~A}$

\section{Conclusions}

The conclusions from this paper can be summarized as follows:

1. A welding speed control system was constructed to control the width of weld bead using ANN. The machine vision system used CCD camera to capture the molten pool image and image processing for determined the width of molten pool.

2. The best result from the experiment that have been performed is the welding process at $105 \mathrm{~A}$ with normalization with the lowest average error and the standard deviation of $0.49 \mathrm{~mm}$ and $0.26 \mathrm{~mm}$, respectively.
3. The best result for difference of manual and machine vision measurement is the welding process at $110 \mathrm{~A}$ with normalization with the lowest average error and the standard deviation of $0.11 \mathrm{~mm}$ and $0.24 \mathrm{~mm}$, respectively.

The authors would like to express their sincere gratitude for the financial supported by PDUPT program of RISTEKDIKTI 2018 with contract number 397/UN2.R3.1/HKP05.00/2018.

\section{References}

1. M.R. Karafi, R. Narimani, Y. Hojjat, and M. Gheybi, The International Journal of Advanced Manufacturing Technology, Study on automatic control of arc gap in robotic TIG welding, 50, 953960, (2010).

2. H. Eisazadeh, D.J. Haines, and M. Torabizadeh, Journal of Materials Processing Technology, Effects of gravity on mechanical properties of GTA welded joints, 214, 1136-1142, (2014).

3. S. Okano and M. Mochizuki, Journal of Materials Processing Technology, Transient distortion behavior during TIG welding of thin steel plate, 241, 103-111, (2017).

4. D. Nagesh and G. Datta, Journal of Materials Processing Technology, Prediction of weld bead geometry and penetration in shielded metal-arc welding using artificial neural networks, 123, 303312, (2002).

5. C. Wu, J. Gao, X. Liu, and Y. Zhao, Proceedings of the institution of mechanical engineers, Part B: Journal of Engineering Manufacture, Vision-based measurement of weld pool geometry in constantcurrent gas tungsten arc welding, 217, 879-882, (2003).

6. J. Smith and W. Lucas, Welding Research Abroad, Vision based systems for controlling the arc welding operation and inspecting the weld bead profile, 46, 10-22, (2000).

7. M.A. Houghton, J.J. Lucas, and W. Lucas, Soldagem \& Inspecao, Vision systems for monitoring and control of arc welding operations, 12, 293-299, (2007).

8. A.S. BASKORO and Y. SUGA. 232 Investigation of Welding Penetration Control in TIG Welding of an Aluminum Pipe Using Vision Sensing. in The Proceedings of the Materials and processing conference 2006.14. 2006. The Japan Society of Mechanical Engineers.

9. S. Chokkalingham, N. Chandrasekhar, and M. Vasudevan, Journal of Intelligent Manufacturing, Predicting the depth of penetration and weld bead width from the infra red thermal image of the weld pool using artificial neural network modeling, 23, 1995-2001, (2012).

10. P. Ghanty, M. Vasudevan, D. Mukherjee, N. Pal, N. Chandrasekhar, V. Maduraimuthu, A. Bhaduri, P. Barat, and B. Raj, Science and Technology of Welding and Joining, Artificial neural network approach for estimating weld bead width and depth 
of penetration from infrared thermal image of weld pool, 13, 395-401, (2008).

11. W. Chen and B. Chin, Welding Journal, Monitoring joint penetration using infrared sensing techniques, 69, 181s-185s, (1990).

12. S. Nagarajan, P. Banerjee, and B. Chin, Transport Phenomena in Materials Processing, Thermal imaging for weld quality control in arc welding processes, 146, 171-178, (1990).

13. H.C. Wikle III, F. Chen, S. Nagarajan, and B.A. Chin, Journal of the Chinese institute of engineers, Survey of infrared sensing techniques for welding process monitoring and control, 21, 645-657, (1998).

14. M. Menaka, M. Vasudevan, B. Venkatraman, and B. Raj, Insight-Non-Destructive Testing and Condition Monitoring, Estimating bead width and depth of penetration during welding by infrared thermal imaging, 47, 564-568, (2005).

15. J. Lee and K. Um, Journal of materials processing technology, A prediction of welding process parameters by prediction of back-bead geometry, 108, 106-113, (2000).

16. N. Nandhitha and N. Manoharan, B., Venkataraman, B., Vasudevan, M., Kalyana Sundaram, P., Raj, B.: Prediction of Torch Current Deviation using Feed Forward Neural Network for Monitoring Lack of Penetration from Thermal Images in GTAW of AISI Stainless Steel, Sheela rani, 316, 271-279, (2009).

17. K. Andersen, G.E. Cook, G. Karsai, and K. Ramaswamy, IEEE Transactions on industry applications, Artificial neural networks applied to arc welding process modeling and control, 26, 824830, (1990).

18. I. Milyardi and A.S. Baskoro. Effect of current and speed on porosity in autogenous Tungsten Inert Gas (TIG) welding of aluminum alloys A1100 butt joint. in IOP Conference Series: Materials Science and Engineering. 2018. IOP Publishing.

19. A.S. Baskoro. Monitoring of molten pool image during pipe welding in gas metal arc welding (GMAW) using machine vision. in Advanced Computer Science and Information System (ICACSIS), 2011 International Conference on. 2011. IEEE. 